\title{
ANTARCTIC ICE-SHEET TOPOGRAPHY AND SURFACE-BEDROCK RELATIONSHIPS
}

\author{
by
}

\author{
N.F. McIntyre
}

(Mullard Space Science Laboratory, University of College London, Holmbury St. Mary, Surrey RH5 6NT, UK)

\begin{abstract}
Mapping the topography of the Antarctic ice sheet has confirmed that there is, typically, a decrease in the wavelength and increase in the amplitude of surface undulations with distance from ice divides. This pattern is distorted by converging ice flow in coastal regions and by other variations in subglacial relief, ice velocity, and viscosity. The near-symmetry of undulations indicates the extent of three-dimensional flow over bedrock peaks. Spectral analyses indicate the greater response of the ice sheet to bedrock features with longer wavelengths. This is affected, and in some cases dominated, by the inhomogeneous and non-isothermal nature of the ice sheet.
\end{abstract}

\section{INTRODUCTION}

With the rapid development of surveying techniques over the last 40 years, the form of the Antarctic ice sheet, on the scale of hundreds of kilometres, has been mapped and described in some detail (for instance, Drewry, 1983; Drewry and Robin, 1983). Such variations can be explained regionally, to a first approximation, by the rheological properties of the ice mass and the major topographic features of the continent. Smaller-scale features, of the order of one to tens of kilometres, are less well documented. Surface undulations (Budd and Carter, 1971), crevasse fields (Rose, 1979), and flow lines (Allison, 1979) have been described and analysed in a number of localised case studies, but not on a continental basis. The first of these is most clearly depicted by the data sources presented below and will form the basis of the ensuing discussion.

Undulations in ice-sheet surfaces have been analysed in detail by several authors and shown to be primarily caused by perturbations in ice flow, induced by varying basal conditions (e.g. Robin (1967)). From such work have come models, which describe the relationship between the lower and upper surfaces of ice masses. Budd (1969, 1970) defined a damping factor, which describes the transfer of features in the basal topography to the ice-sheet surface, in terms of ice thickness, mean velocity, and viscosity of the ice mass. Applying to a uniform ice mass, sliding down an incline, with a uniform distribution of slopes, this model predicts the rapid damping of features with short wavelengths relative to the ice thickness. It also predicts the dominant response of bedrock undulations, with wavelengths 3.3 times the ice thickness.

In a more recent analysis, Hutter and others (1981) derived a filter function, which defined the fraction of bedrock amplitudes transmitted to the ice sheet surface at certain wavelengths. Although applying to bedrock and ice surfaces which depart only slightly from being parallel and to small bedrock undulations relative to the ice thickness, Hutter and others concluded that the transfer of bedrock irregularities to the ice sheet surface is related to the undulation's wavelength. The filter function is strongly dependent on the inclination of the ice mass, but, as velocity increases, the importance of inclination is reduced. Damping is also increased by vertical temperature gradients within the ice mass.
Whillans and Johnsen (1983) developed a further theory of bedrock-surface relationships, in which flow variations were superimposed on an average regime. Measured surface and bedrock profiles were used to indicate the differences in basal regime that cause the observed ice-flow variations. Resulting basal variations were used to infer some features of the dominant physical processes. The model points to the effects of types of motion at the bed; variations in shear stress and sliding, along the Byrd Station Strain Network, were found to be of greater direct importance to the resulting surface terrain than was the flow of ice into, and out of, basal topography.

Two recently published papers (Reeh and others, 1985; Dahl-Jensen, 1985) employed a first-order, ice-sheet model in which 'basic' and 'perturbed' flow are distinguished. In both papers, vertical variations in temperature and ice rheology are taken into account and it is concluded that consideration of such variations is essential for explaining observed surface-bedrock relationships.

The purpose of this paper is to decribe the topographic variability of the Antarctic ice sheet, on scales of one to tens of kilometres. More detailed studies are then made of the response of the ice-sheet surface to basal conditions, in a variety of glaciological regimes, thereby enabling testing of models, which describe this relationship.

\section{SOURCES OF DATA}

One of the most successful ice-sheet profiling techniques employed in the polar regions has been airborne radio echo-sounding. The joint programme, run between 1967 and 1979 by the National Science Foundation (NSF) and the Scott Polar Research Institute (SPRI) and, latterly, with the Technical University of Denmark (TUD), surveyed over $6.8 \times 10^{6} \mathrm{~km}^{2}$ (approximately $50 \%$ of the Antarctic ice sheet) on a grid of 50 to $100 \mathrm{~km}$. Accuracy, coverage, and products of this programme have been described in detail elsewhere (for instance, Drewry, 1983).

Throughout the 1977-78 and 1978-79 NSF-SPRI-TUD radio echo-sounding flights, aircraft terrain clearance and pressure altitude were logged at 4 or $8 \mathrm{~Hz}$ by the Hercules C-130's on-board recording system, thereby enabling determination of ice-sheet surface elevations along the flight lines (for instance, Swithinbank and others, 1976). With an estimated $65 \%$ of the two seasons' flights within the radar altimeter's upper operational limit of $1524 \mathrm{~m}$, these data represent $55000 \mathrm{~km}$ of detailed, ice-sheet profiling, at a high density. This will form the basis of much of the ensuing description and analysis of the Antarctic ice sheet's surface morphology.

Surface elevations derived from the aircraft's altimeters are estimated to have a relative accuracy of $2 \mathrm{~m}$ (McIntyre, 1983). The determination of absolute altitudes by barometric methods is dependent on the temporal and spatial stability of pressure surfaces, variations of which are associated with weather systems. Sections of altimetry data, analysed here, were therefore kept comparatively short (mostly less than $200 \mathrm{~km}$ ) and were used to calculate only relative surface elevations.

Both lowpass and bandpass digital filters were applied 


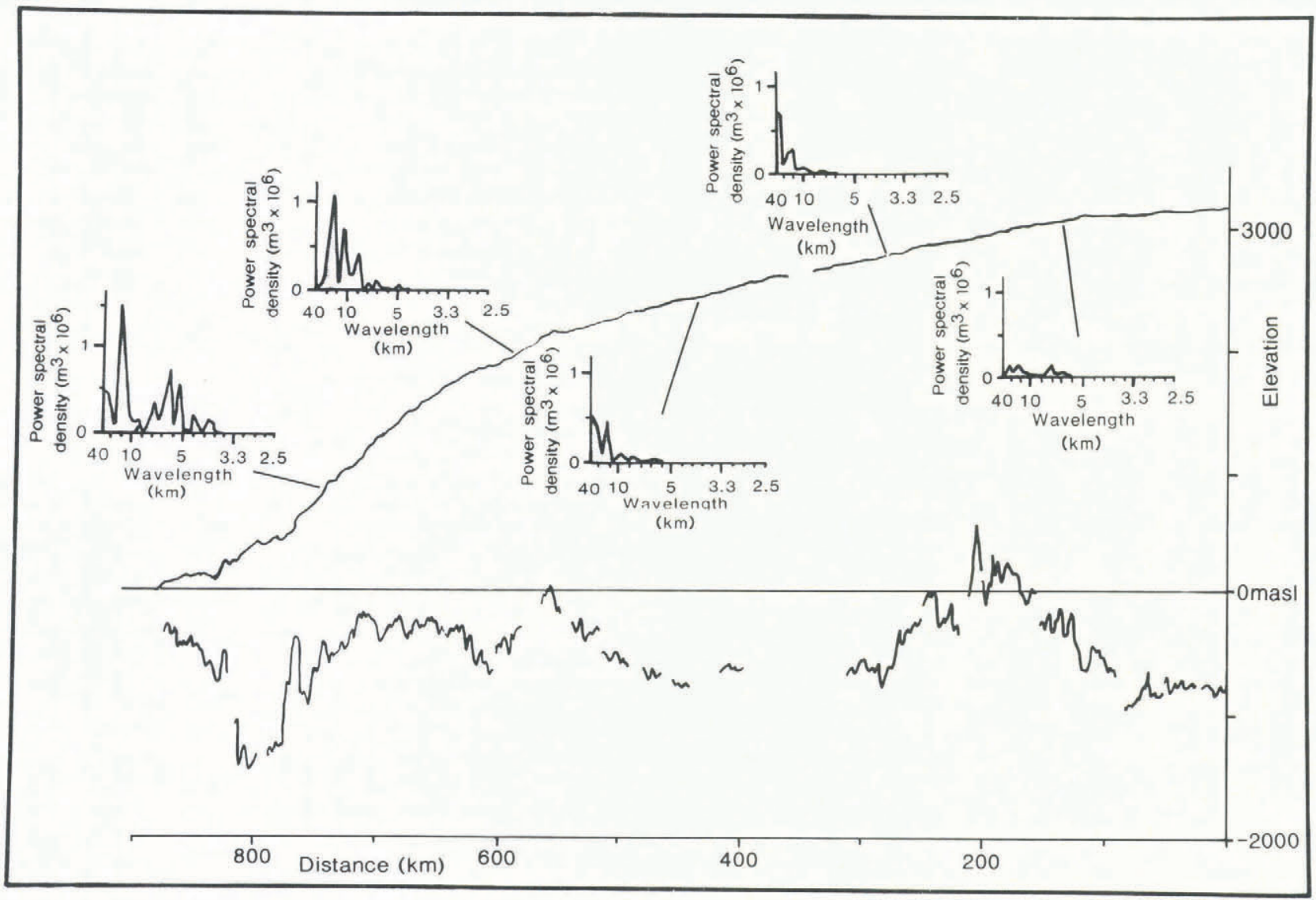

Fig.1. Profiles of upper and lower surfaces of the ice sheet, from aircraft altimetry and radio echo-sounding, respectively. Data are from two, virtually coincident flights down a flowline between Dome Circe and the Wilkes Land coast at $120^{\circ} \mathrm{E}$. Spectra have been produced from 5 segments of bandpass-filtered altimetry of the ice-sheet surface, each $200 \mathrm{~km}$ long.

to the altimetric profiles, used for statistical and spectral analysis later in this paper. A lower limit on wavelength of $500 \mathrm{~m}$ was selected, to minimize the small-scale effects of snow dunes, sastrugi, and system noise, which were not of primary interest to the present investigation of ice-flow features. A cut-off of $50 \mathrm{~km}$ was chosen as the upper bandpass limit, on the basis of wavelengths identified in the data.

\section{ANTARCTIC ICE SHEET TOPOGRAPHY}

\section{Regional topography}

Figure 1 shows ice-sheet surface and bedrock profiles between Dome Circe and the Wilkes Land coast at $120^{\circ} \mathrm{E}$ the five spectra have been produced by applying a Fast Fourier Transform to overlapping, 200-km sections of the ice sheet's upper surface. Regional ice thicknesses decrease in a generally uniform manner and ice velocities and temperatures may be assumed to increase fairly regularly with distance from the ice divide.

The spectra provide details of the increasing topographic roughness, with distance from the ice divide, a trend which can also be seen in the surface profile itself. Two particular points should be noted. First, there is a marked increase in the energy of each spectrum as one approaches the coast. The RMS deviation of the surface, the square root of the zeroth moment of each spectrum, increases from under 2 to $12.2 \mathrm{~m}$. Secondly, there is the relative contribution of different wavelengths to deviations from the regional, ice-sheet surface changes. Near the divide, minor spectral peaks occur at several wavelengths, but, as velocities increase downslope, the contributions from wavelengths typically greater than $25 \mathrm{~km}$ become increasingly dominant. While long wavelengths occur in the coastal region, the dominant peak is at $12 \mathrm{~km}$; considerable energy also exists at shorter periods.

These patterns of increasing roughness and dominance of shorter undulation wavelengths, as one approaches the thinner, faster-flowing ice, near the coast, are typical of much of East Antarctica, which conforms to a near-parabolic profile (Vialov, 1958). They confirm the trends noted in Greenland and on the Wilkes ice cap by Budd and Carter (1971), but extend farther inland and encompass considerably larger undulations, wavelengths of 2 to $40 \mathrm{~km}$ being observed.

The transition in terrain across the ice sheet may also be considered in terms of bandpass-filtered gradients (Figure 2). Regional slopes (indicated by mean values) increase from zero, at the divides, to 2 or $3 \%$ at the margin, while deviations may rise to approximately $8 \%$ in extreme cases (Figure $2 \mathrm{a}$ to $\mathrm{d}$ ).

The distribution of undulations in coastal parts of the Antarctic is far from uniform. The rough terrain, associated with converging ice flow through ice streams and outlet glaciers, is typically separated by a series of domed divides, on which surface features are smaller or absent. These appear to be glaciologically stagnant, with lower ice velocities and possibly lower basal temperatures than those of the more active outlets (McIntyre, 1985). Mean gradients of the lower sections of outlet glaciers and ice streams (Figure $2 \mathrm{e}$ and $\mathrm{f}$ ) are often less than those of adjacent areas of linear or divergent flow. Local slopes may, however, be substantial, with gradients of up to $10 \%$. The contrasting effects of different flow regimes, thought to predominate in the thick, basally-lubricated Institute Ice Stream and the thinner, fast-flowing Thwaites Glacier, are clearly illustrated.

The preceding characterisation of surface topography is based on a near-parabolic ice sheet profile, such as that in Figure 1, which is representative of much of East Antarctica. Local effects, associated with variations in subglacial relief, ice velocity and viscosity, distort the regular alteration of surface topography across the ice sheet.

Undulation symmetry

The orthogonal intersection of altimetric flight lines enables investigation of the symmetry of surface undulations 


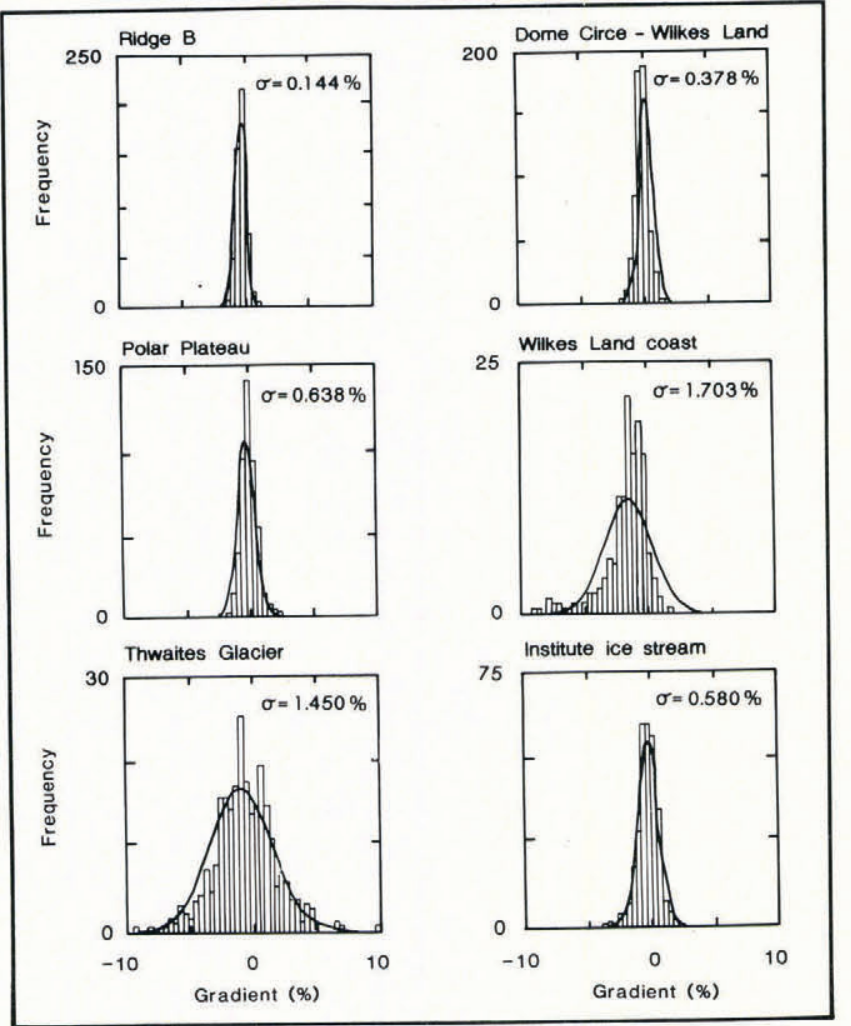

Fig.2. Frequency histograms of gradients of $1 \mathrm{~km}$ slope segments, calculated by fitting a linear regression to lowpass-filtered, altimetric profiles of the ice-sheet surface. Standard deviations $(\sigma)$ are given for each distribution. Gaussian curves have been added for comparative purposes.

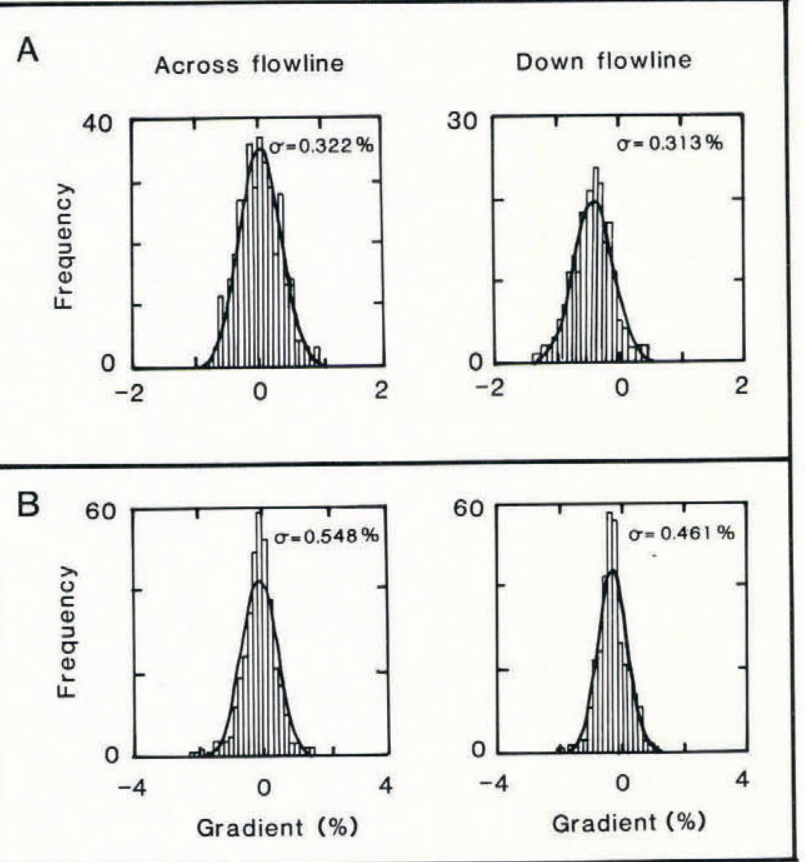

Fig.3. Frequency histograms of lowpass-filtered, ice-sheet surface gradients (derived as in Figure 2), both normal and parallel to flow lines. A: The head of Ice Stream D, in Marie Byrd Land. B: $40 \mathrm{~km}$ inland of the Wilkes Land coast at $120^{\circ} \mathrm{E}$. Standard deviations $(\sigma)$ and Gaussian curves are shown for each distribution.
(Figure 3). The distribution of gradients, normal and parallel to flowlines, is similar in form and magnitude. The small departures from symmetry, even for undulations in the thinner ice of coastal regions (Figure 3b), suggest that ice flow over subglacial peaks produces similar stress gradients in longitudinal and tranverse directions. Thus, approximately half of the stress gradients involved in ice flow over subglacial features are absorbed by the lateral displacement of ice. This supports the suggestion (Robin and Millar, 1982) that three-dimensional motion can sometimes (although not always (Whillans and others, 1984)) be an important element of ice flow.

\section{SURFACE-BEDROCK RELATIONSHIPS}

\section{Surface-undulation wavelength and ice thickness}

Budd's (1970) treatment of ice flow over bedrock perturbations predicted the dominance of surface wavelengths 3.3 times the mean ice thickness and has been confirmed by field evidence (Beitzel, 1970; Budd and Carter, 1971). This can be further tested with Antarctic data (previous section; McIntyre, 1983), by plotting dominant surface wavelengths $\left(\lambda_{d}\right)$ against mean ice thicknesses (Z) (Figure 4). There appears to be correlation, although not centred on $\lambda_{d}=3.3 Z$. Budd's (1970) linear relationship does not describe adequately the full range of data presented here. Either a high-order curve, or the more vaguely-phrased conclusion, from Budd's (1969) analysis, that 'surface undulations of wavelengths 2 to 10 times the ice thickness may tend to predominate', seems to be more appropriate.

The data presented in Figure 4 come from a wide range of glaciological regimes and the lack of agreement with theory may result from violation of the model's assumptions. In any circumstances, a certain amount of scatter of data points is to be expected, because of the

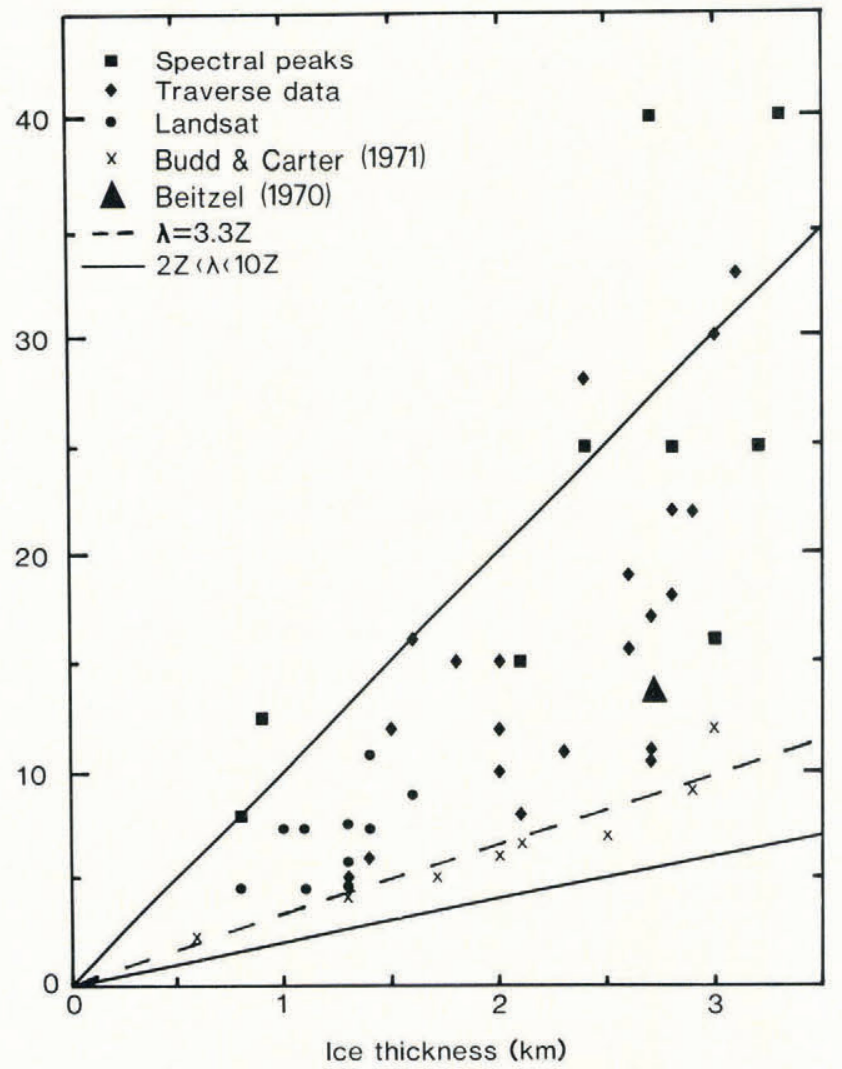

Fig.4. Relationship between mean ice thickness (from Drewry, 1983) and dominant surface undulation wavelengths, from a variety of data sources. Spectral plots, traverse data, and Landsat data are from McIntyre (1983). Data from Budd and Carter (1971) are from Greenland. The mean of data from Beitzel (1970) is given by one point. $\lambda=3.3 \mathrm{Z}$ (Budd, 1970) is shown by a dashed line and the limits $2 \mathrm{Z}<\lambda_{\mathrm{d}}<10 \mathrm{Z}$ (Budd, 1969) by solid lines. 
Ridge B
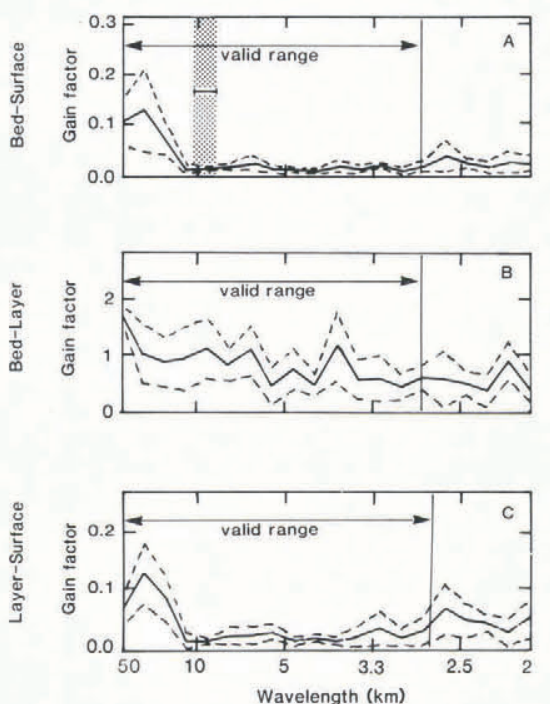

Lennox King Glacier
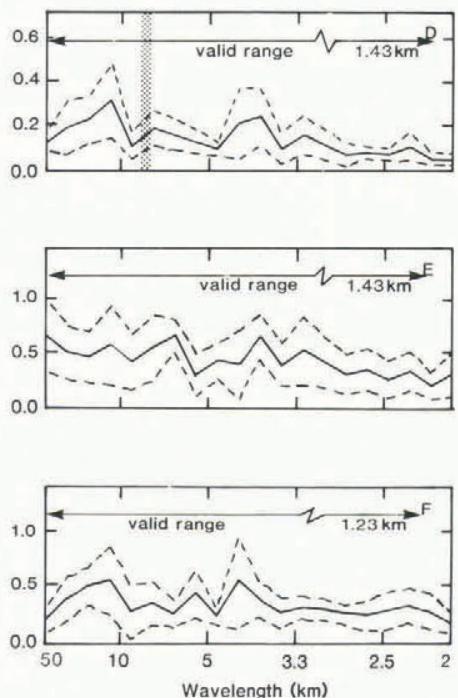

Reedy Glacier

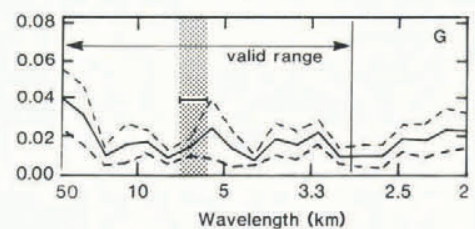

Fig.5. Frequency-response functions of bandpass-filtered profiles of bedrock, the lowest layer, and the ice-sheet surface, expressed as non-dimensional gain factors against undulation wavelength. Dashed lines show 95\% confidence limits. Data are from flowlines downstream of Ridge B (78.5 $\mathrm{S}$ $102^{\circ} \mathrm{E}$ ) and leading to the Lennox King and Reedy Glaciers (both in the southern Transantarctic Mountains). Vertical bars show the expected maximum response of the surface to bedrock undulations of 3.3 ice thicknesses (Budd, 1970), with a range of one standard deviation. Valid ranges are defined by Equation 1.

averaging of ice thicknesses and the different errors associated with each source,

Surface response to bedrock undulations

A more thorough investigation of surface-bedrock relationships may be carried out with spectral analysis, (Beitzel, 1970; Budd and Carter, 1971). Cross-spectral analyses were carried out on bandpass-filtered profiles of surface, bedrock, and, where its continuity permitted, the lowest layer, the latter defining the upper limit of the basal echo-free zone (Millar, 1981). Frequency-response functions were calculated and are presented for three profiles (Figure $5)$, as non-dimensional gain factors. These indicate the proportionate magnitude of output (profiles of surface and lowest layer) for a unit change in input (profiles of lowest layer and bedrock), at any given frequency. They are, therefore, directly equivalent to the transfer functions of Hutter and others (1981) and of Whillans and Johnsen (1983). Relevant physical parameters are given in Table 1.

The main limitation of the present data involves incomplete migration of the radio echo-sounding profiles. Layering within the ice mass, with amplitudes several hundred metres greater than those of the bedrock, suggests that the true basal profile has not been produced by migration and that echoes from valleys are still partly obscured by hyperbolae from adjacent peaks. This is supported by gain factors greater than 1.0 (Figure 5, B). Also, radio echo-sounding cannot detect depressions in the bedrock profile less than a critical wavelength, $\lambda_{c}$, such that the radius of curvature at the bottom of the hollow equals the range to that point $(r)$. Thus

TABLE 1: PHYSICAL PARAMETERS RELEVANT TO THE THREE PROFILES TO WHICH CROSS-SPECTRAL ANALYSIS HAS BEEN APPLIED (FIGURE 5). MOST MEASURED VALUES ARE FROM DREWRY (1983). BASAL TEMPERATURES HAVE BEEN DERIVED USING THE MODEL OF BUDD (1969).

\begin{tabular}{|c|c|c|c|}
\hline Nean Values & $\underline{\text { Ridge } B}$ & $\begin{array}{c}\text { Lennox King } \\
\text { Glacier }\end{array}$ & $\begin{array}{l}\text { Reedy } \\
\text { Gilacier }\end{array}$ \\
\hline length $(\mathrm{km})$ & 271 & 285 & 235 \\
\hline Thickness ( $m$ ) & 2700 & 2450 & 1800 \\
\hline Depth to lowest layer $(\%)$ & 90 & 85 & 75 \\
\hline RNIS bedrock amplitude $(\mathrm{m})$ & 150 & 45 & 355 \\
\hline Accumulation rate $\left(\mathrm{m} \mathrm{a}^{-1}\right)$ & 0.04 & 0.08 & 0.11 \\
\hline Balance velocity $\left(m a^{-1}\right)$ & 1 & 2 & 6 \\
\hline Velncity/thickness $\left(a^{-1} \times 10^{-3}\right)$ & 0.37 & 0.82 & 3.33 \\
\hline Driving stress (kra) & 20 & 30 & 100 \\
\hline Annual surface temperature $\left({ }^{\circ} \mathrm{C}\right)$ & -59 & -55 & -36 \\
\hline Basal temperature $\left({ }^{\circ} \mathrm{C}\right)$ & -24 & -18 & -2 \\
\hline Surface inclination $(\%)$ & -0.11 & -0.16 & -0.56 \\
\hline
\end{tabular}




$$
\lambda_{c}=2 \pi(b r)^{1 / 2}
$$

where $\mathrm{b}$ is the bedrock amplitude (Budd, 1969)

Gain factors for the three bedrock-surface cross-spectra (Figure 5, A, D, and G) show general trends of increasing response with undulation wavelength, as predicted by the models of Hutter and others (1981) and Whillans and Johnsen (1983). The latter two cross-spectra, in particular, show peaks in response at several wavelengths, but in none of the three is there a maximum at about three ice thicknesses, as suggested by Budd (1970).

Gain factors for the profile downstream of Ridge B show there to be strikingly different responses to basally-induced stresses in the lower (Figure 5, B) and upper (Figure 5, C) parts of the ice mass. The thin, basal echo-free zone has a very high response throughout, confirming that the basal ice appears to be a zone of low viscosity (Table 1), which reacts sensitively to the bedrock profile. The very much colder, upper body of the ice mass, however, reacts more as a rigid slab to basally-generated stresses, in which all but the longest wavelengths (those over $20 \mathrm{~km}$ ) are filtered out. Thus, where there is a significant discontinuity in the ice column, as appears to be the case downstream of Ridge $\mathrm{B}$, the major stress variations are governed primarily by the higher, and more uniform, viscosity and velocity of the upper layers (Budd, 1969). These different responses indicate the effect of vertical variations in temperature and rheology on ice flow and the ice sheet's resulting surface topography (Hutter and others, 1981; Whillans and Johnsen, 1983; Reeh and others, 1985; Dahl-Jensen, 1985).

The surface response of the profile leading to Reedy Glacier (Figure 5, G), with maximum gain factors of 0.04 , is particularly low, compared with the other profiles. Its severe basal topography, steep surface slope, relatively thin ice, and higher balance velocity (Table 1) would suggest, by all models discussed above, a higher surface gain than for the transects downstream of Ridge $B$ and leading to the Lennox King Glacier. The surface response appears to be limited by the over-riding effects of vertical variations in temperature. While the other two profiles seem to be frozen to bedrock throughout, the profile leading to Reedy Glacier is at pressure melting point. The dominant effect of vertical temperature variations, in attenuating the transfer of bottom undulations to the surface, was recognised by Hutter and others (1981), Whillans and Johnsen (1983), Reeh and others (1985) and Dahl-Jensen (1985). In addition, the ratio of velocity to thickness (Table 1), proportional to the mean shear strain rate through the ice column, indicates a considerably higher, vertical strain-rate gradient for the Reedy Glacier profile than for the other two. A substantial, basal echo-free zone, in this region of considerable basal relief, may indicate the presence of shear zones within the ice mass, which elsewhere have been shown to separate the upper body of the profile from less active ice in topographic lows (Colbeck and others, 1978). This would result in a smoother, false bedrock and the low response of the surface, as observed.

\section{CONCLUSIONS}

Consideration of the relationship between the upper and lower profiles of the Antarctic ice sheet has shown that, unlike results from previous analyses, there is no bedrock wavelength which is preferentially transmitted to the ice sheet surface. This confirms predictions by Hutter and others (1981) and Whillans and Johnsen (1983) that there is increasing surface response at longer wavelength. The inhomogeneous and non-isothermal nature of the ice sheet was, however, found to be of particular importance in determining its response to boundary conditions. This was demonstrated for cases in which there are thought to be significant vertical variations in temperature and viscosity. Such rheological and thermal inhomogeneity points to the value of multi-layer models, which can incorporate variations in viscosity and velocity with depth (for instance, Dahl-Jensen, 1985).

This investigation has also demonstrated the importance of carrying out analyses in three dimensions, since the lateral response of ice sheets can be a first-order effect on perturbations to ice flow. More complex modelling of the flow of ice masses will require commensurately more accurate and detailed sources of data, with which to test and validate theoretical developments. This points to the need for precise survey techniques, such as satellite radar altimetry, which have the potential to provide topographic maps, accurate at the kilometre-scale, for investigations such as described here

\section{ACKNOWLEDGEMENTS}

Much of the work described here was carried out at the Scott Polar Research Institute while the author was in receipt of a studentship from the UK Natural Environment Research Council. Thanks are due to the Sea Ice Group at the Scott Polar Research Institute for the use of software and to Dr G. de Q. Robin and Dr K. Hutter for critical reviews.

\section{REFERENCES}

Allison I F 1979 The mass budget of the Lambert Glacier drainage basin, Antarctica. Journal of Glaciology 22(87): 223-235

Beitzel J E 1970 The relationship of ice thicknesses and surface slopes in Dronning Maud Land. International Association of Scientific Hydrology Publication 86 (ISAGE): 191-203

Budd W F 1969 The dynamics of ice masses. ANARE Scientific Reports Ser A(IV). Glaciology. Publication 108

Budd W F 1970 Ice flow over bedrock perturbations. Journal of Glaciology 9(55): 29-48

Budd W F, Carter D B 1971 An analysis of the relation between the surface and bedrock profiles of ice caps. Journal of Glaciology 10(59): 197-209

Colbeck S C, St Lawrence W, Gow A J 1978 Creep rupture at depth in a cold ice sheet. Nature 275(5682): 733

Dahl-Jensen D 1985 Determination of the flow properties at Dye 3, south Greenland, by bore-hole-tilting measurements and perturbation modelling. Journal of Glaciology 31(108): 92-98

Drewry D J (ed) 1983 Antarctica: glaciological and geophysical folio. Cambridge, University of Cambridge. Scott Polar Research Institute

Drewry D J, Robin G de Q 1983 Form and flow of the Antarctic ice sheet during the last million years. In Robin $\mathrm{G}$ de $\mathrm{Q}$ (ed) The climatic record in polar ice sheets. Cambridge, Cambridge University Press: 28-38

Hutter K, Legerer F, Spring U 1981 First-order stresses and deformations in glaciers and ice sheets. Journal of Glaciology 27(96): 227-270

McIntyre N F 1985 The dynamics of ice-sheet outlets. Journal of Glaciology 31(108): 99-107

McIntyre N F Unpublished The topography and flow of the Antarctic ice sheet. (PhD thesis, Cambridge University, 1983)

Millar D H M Unpublished Radio-echo layering in polar ice sheets. (PhD thesis, University of Cambridge, 1981)

Reeh N, Johnsen S J, Dahl-Jensen D 1985 Dating of the Dye 3 deep ice core by flow model calculations. In Langway C C Jr, Oeschger H, Dansgaard W (eds) Greenland ice core: geophysics, geochemistry, and the environment. Washington, DC, American Geophysical Union: 57-65 (Geophysical Monograph 33)

Robin G de Q, Millar D H M 1982 Flow of ice sheets in the vicinity of subgiacial peaks. Annals of Glaciology 3: 290-294

Rose K E 1979 Characteristics of ice flow in Marie Byrd Land, Antarctica. Journal of Glaciology 24(90): 63-75

Vialov S S 1958 Regularities of glacial shields movement and the theory of plastic viscous flow. International Association of Scientific Hydrology Publication 47 (Symposium of Chamonix - Physics of the Motion of Ice): 266-275

Whillans I M, Johnsen S J 1983 Longitudinal variations in glacial flow: theory and test using data from the Byrd Station strain network, Antarctica. Journal of Glaciology 29(101): $78-97$

Whillans I M, Jezek K C, Drew A R, Gundestrup N 1984 Ice flow leading to the deep core hole at Dye 3 Greenland. Annals of Glaciology 5: 185-190 